\title{
Therapy of congenital glaucoma
}

\author{
Franz Grehnn ${ }^{1,2}$, Esther Hoffmann ${ }^{2}$ \\ 'Department of Ophthalmology, University Hospitals Würzburg, Germany \\ Head of the Department: Univ.-Prof. Dr. med. Jost Hillenkamp, FEBO \\ ${ }^{2}$ Childhood Glaucoma Center, Department of Ophthalmology, Universitätsmedizin Mainz, Germany \\ Head of the Department: Univ.-Prof. Dr. Norbert Pfeiffer
}

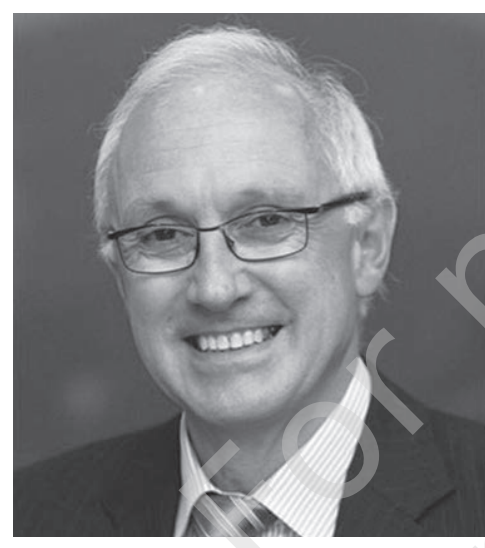

\section{ABSTRACT}

The primary therapy of all forms of primary and secondary congenital glaucoma is surgical. In the last few decades, the options for customized surgical approach to different types of childhood glaucoma have significantly developed. In particular, circumferential trabeculotomy has shown some superiority over conventional trabeculotomy and is now also used to treat secondary congenital glaucoma. Goniotomy is still a valid alternative. Tube implants in childhood glaucoma still need improvements.

Key words: congenital glaucoma, aphakic glaucoma, trabeculotomy, goniotomy, tube implantation 


\section{INTRODUCTION}

Congenital glaucoma is a rare disease which can lead to significant and permanent visual impairment or blindness if not treated adequately at an early stage. It affects about one of 12,000-18,000 newborns during the first year of life in western countries but may be much more frequent in populations where consanguinity is common. Severe cases may be present at birth, while others, in particular unilateral mild cases, become manifest only some weeks or months after birth. As an estimate, countries like Germany or Poland will have about 7 cases per 100,000 newborns or 56 and 25 new cases, respectively, of primary congenital glaucoma per year.

\section{NOMENCLATURE}

Congenital glaucoma (CG) is a general term that comprises various forms which are part of childhood glaucoma "family" (the other being infantile and juvenile open angle glaucoma). The nomenclature has recently been more precisely defined by the Congenital Glaucoma Research Network and published in a Consensus book [1]. Hence, when discussing treatment options, one must distinguish between these different forms, because one single treatment does not fit for all forms of CG.

Primary congenital glaucoma is the condition where no other abnormalities exist besides IOP elevation and subsequent ocular signs. Secondary congenital glaucomas comprise those (1) with ocular and those (2) with systemic non-acquired abnormalities, as well as those (3) with acquired abnormalities. A separate form is (4) secondary glaucoma after surgery for congenital cataract (aphakic glaucoma).

In western populations, primary CG, secondary CG and aphakic glaucoma each comprise grossly $1 \frac{1}{3}$ of cases.

\section{DIAGNOSTIC SIGNS}

All forms of congenital glaucoma typically have considerably elevated IOP. Therefore, the damage to the optic nerve and the damages secondary to it at the anterior segment are intraocular pressure (IOP) related. This pathophysiology is probably different from POAG of the adult at advanced age, where other mechanisms of damage such as compromised microcirculation [2] and others may play a more prominent role. As a consequence, treatment in CG exclusively aims at lowering IOP.

However, for pragmatic purposes of diagnosis, IOP is not the only (and even not the most significant) parameter, as examination usually is performed under general anesthesia when IOP is artificially lowered by the tranquilizing effect of many anesthetic drugs. However, the development of a standardized anaesthesia protocol as used in our center, helps to measure IOP more reliably at different time points during initiation of anaesthesia. The most reliable sign, if present, are Descemet's tears of the cornea (Haab's striae), because they develop only if periods of high IOP occur during in the first or second year of life (forceps delivery was a former cause in complicated deliveries, but is no more in use nowadays). Typically, the corneal epithelium and stroma are cloudy and the corneal diameter is enlarged (Caliper measurement). Similarly, due to general stretching of the eyeball, axial length is increased. Ultrasound axial length measurements are very valuable, in particular for follow up and in comparison to the contralateral eye in unilateral cases. Excavation of the optic nerve head is usually present in longstanding cases, but not on a regular basis in babies less than 4 or 6 months of age. Its diagnostic value is therefore limited in early onset cases. Cupping of the ONH may disappear after IOP lowering.

\section{TREATMENT OPTIONS}

The primary therapeutic step in most forms of congenital glaucoma is incisional surgery. These small patients require special and delicate surgical techniques in unfamiliar anatomical conditions and need a specialized team for anesthesia and occasionally a pediatric ICU on place. Postoperatively, a structured orthoptic follow-up to secure visual development and avoid amblyopia is essential. Therefore, surgery should be performed only by experienced surgeons in centers that have these facilities routinely available [3].

\section{Bridging medical therapy}

As there may be a time interval between diagnosis and surgical treatment options, a bridging medical antiglaucoma therapy is sometimes needed. However, in primary congenital glaucoma and in many secondary congenital glaucomas an immediate scheduling for primary surgery must be recommended. In aphakic childhood glaucoma relapses may respond sufficiently to medical therapy and subsequent surgery should be balanced to surgical risks and success rates.

\section{The trabecular meshwork in congenital glaucoma}

There is a general consensus that delayed or malformed development of the trabecular meshwork is the primary cause of IOP elevation in congenital glaucoma. There are several studies that show that aqueous flow through the corneoscleral trabecular meshwork is still impeded by major sheaths of overlying uveal meshwork in the last month of pregnancy and early months after birth whereas Schlemm's canal is already fully developed (see surgical results below). This is the basis of trabecular surgery in congenital glaucoma. 


\section{SURGICAL OPTIONS}

There has been a long tradition to use either trabeculotomy or goniotomy as a primary surgical approach in primary congenital glaucoma, depending mostly on the experience of the surgeon with the respective technique. The decision for one of these procedures mostly depends on the clarity of the cornea and the experience of the surgeon. During the last 5-8 years, circumferential trabeculotomy with an illuminated micro-catheter has become popular and is now used in many specialized childhood glaucoma centers. In bilateral cases we usually operate only one (the more affected) eye in one session and the second eye within 1 to 4 weeks if the first eye develops favourably. However, some surgeons advocate bilateral simultaneous operations, in particular in goniotomy to reduce the number of general anesthesias.

\section{Goniotomy}

Goniotomy was first introduced by Barkan for congenital glaucoma in the early 1940 [4]. Before that, congenital glaucoma was not treatable and frequently led to blindness. Goniotomy remained the operation of choice until trabeculotomy became available in the 1960s, but still has preserved its value as a very effective procedure. The visualization of the angle during this operation is nowadays performed and facilitated via a direct gonioscope (Barkan; Swan-Jacob) using an angled (30-45 degree) operating microscope and an anterior chamber maintainer with infusion or viscoelastics. About 90-120 degree of the trabecular meshwork and Schlemm's canal can be opened with a lateral limbal approach. Experienced surgeons also can handle a nasal approach as in newborns the nose is relatively flat. With the combination of both approaches, $2 / 3$ of the circumference can be opened if needed. Frequently, an anterior insertion of the iris is present and goniotomy can achieve a falling back of the peripheral iris with widening of the chamber angle in a controlled manner. Another advantage of goniotomy is the fact that this approach does not include a conjunctival dissection. Therefore, later filtering surgery is not affected by a history of previous conjunctival surgery. However, when the cornea is not clear, the visualization of the angle may be difficult despite corneal epithelial abrasion, in particular with stromal opacities such as in Peters anomaly. Despite its conceptual simplicity, goniotomy is a technically delicate procedure, and the surgeon must take care not to tear off the iris base or create an cyclodialysis cleft. Touching the lens and iris should be avoided (a constricted pupil helps). Postoperative pilocarpine eye drops for some weeks may keep the trabecular meshwork open.

\section{Results of goniotomy}

Initial IOP control was achieved in 70-93\%, but long-term success decreased to $60 \%$ [5]. In a retrospective study,
Meyer et al. [6] found equal success rates of appr. 70-71\% comparing goniotomy and trabeculotomy (see below) after follow up of 2-5 years, whereas Girkin et al. [7] found the success of goniotomy as low as $54 \%$.

\section{Classical trabeculotomy}

Trabeculotomy's history goes back to Redmond Smith in UK who used a suture to open Schlemm's canal into the anterior chamber by $1 / 2$ circumference [8]. Trabeculotomy with a metal probe was popularized by Burian and Allen [9], Luntz [10] and McPherson [11] in the US, and mostly by Harms in Europe [12] and by Sampaolesi in South America [13].

The surgical technique has changed over time. While a radial incision was originally used to open Schlemm's canal as an $a b$ externo approach, today many surgeons prefer a two-level scleral dissection to Schlemm's canal. This technique is derived from deep sclerectomy/canaloplasty and is also very helpful in circumferential trabeculotomy: after separating the conjunctiva from the scleral surface (limbusor fornix-based), a 3-4 × $4 \mathrm{~mm}$ half-thickness scleral flap is created and advanced to about $1 \mathrm{~mm}$ into the clear cornea. A second deep flap of somewhat smaller size is dissected down closely to the ciliary body, leaving only a very thin sheath of scleral tissue over the ciliary body. When advancing this dissection plane anteriorly, one can reliably open Schlemm's canal anterior to the striated scleral spur fibers. The outer wall of Schlemm's canal is then part of the second flap while the inner wall and the trabecular meshwork remain intact. On each side of the lateral incision, the ostium of the canal becomes visible and accessible (usually a fine strand of blood reflux occurs). These entrances can be used for introducing the metal probe trabeculotome metal probe. Various metal probes are available: The original Harms (without handle) and the Mc Pherson (with handle) probe have two branches and the Mackensen probe (with handle) has one branch. Care must be taken not to tear off the Descemet's membrane. If the pivot point is well controlled, the central Descemet-trabecular membrane can be preserved. A reflux bleeding from the opened Schlemm's canal into the anterior chamber is not uncommon and can be immediately stopped by injecting BSS through a paracentesis to increase the IOP. If the Descemet-trabecular membrane is accidentally or purposely opened, an iridectomy is useful to avoid adherence of the iris base. In very small babies, the second flap can be sutured back, while in more advanced cases the second scleral flap can be removed to create some additional filtration (trabeculo-trabeculectomy) - [14, 15]. Some authors advocate a simultaneous combined trabeculotomy-trabeculectomy in primary or advanced cases $[1,16]$. We have successfully used this method as a second approach if the first trabeculotomy was not sufficiently effective, in particular in advanced cases. 


\section{Circumferential trabeculotomy}

Circumferential trabeculotomy (fig. 1) has a long history (Redmond Smith - see above) and was occasionally used in the 1990ies with a suture [17], long before the illuminated micro-catheters became in use in 2010 [18]. Using the illuminated catheter probing of Schlemm's canal is a safer procedure than suture trabeculotomy because the surgeon can visualize the tip of the probe during advancing it and can immediately recognize if the tip enters the subciliary space or the anterior chamber. Obstacles by membranes or collector channels can be localized and measures can be taken to overcome these stops. Opening of 360 degree of the trabecular meshwork is technically feasible in most cases. In our own experience [19] most of the probings were successful when either a clockwise or a counter-clockwise direction is used and if one patiently tries to overcome any obstacle that sometimes may show up. Surprisingly, even very small and even premature babies and all types of primary and secondary childhood glaucomas could be successfully probed. A viscoelastic is helpful to maintain the anterior chamber and secure the lens and iris. Intracameral acetylcholine should be used to constrict the pupil. By pulling both ends of the catheter, the trabecular meshwork is opened with little force. If there is too much resistence at the beginning, it is helpful to use a simultaneous additional metal probe trabeculotomy before completing the 360 degree circumference with the catheter. When carefully pulling the two ends of the catheter at the end of the tearing procedure the exposed Descemet-trabecular membrane can be preserved and an iridectomy can be avoided.

\section{Results of circumferential trabeculotomy}

In circumferential trabeculotomy it is assumed that the complete opening of the malformed trabecular meshwork would give access to all collector channels and thereby lower IOP better than opening only a limited sector as in conventional trabeculotomy or goniotomy. To prove this hypothesis, several randomized comparative studies have been undertaken. Shakraval et al. [20] found a significantly higher absolute success rate after 1 year in circumferential trabeculotomy (80\%) vs. conventional trabeculotomy (60\%). El Sayed and Gawdat [21] also reported superiority of circumferential trabeculotomy in a randomized series of 62 patients. When opening Schlemm's canal twice with a rigid probe using two entry sites, the success rate equals that of circumferential microcatheter trabeculotomy [22]. Circumferential microcatheter trabeculotomy was shown to be equally effective as combined trabeculotomy-trabeculectomy [15]. Circumferential trabeculotomy has been compared in non-randomized large retrospective studies [23, 24] showing superiority over conventional surgery (trabeculotomy, goniotomy).

\section{FIGURE ( 1}

Circumferential Trabeculotomy. A. Dissection of superficial and deep scleral flap to expose Schlemm's canal ostia. B. Blinking microcatheter tip (red) to locate the catheter during probing of Schlemm's canal. C. Microcatheter visible in the anterior chamber during tearing of trabecular meshwork (arrows).
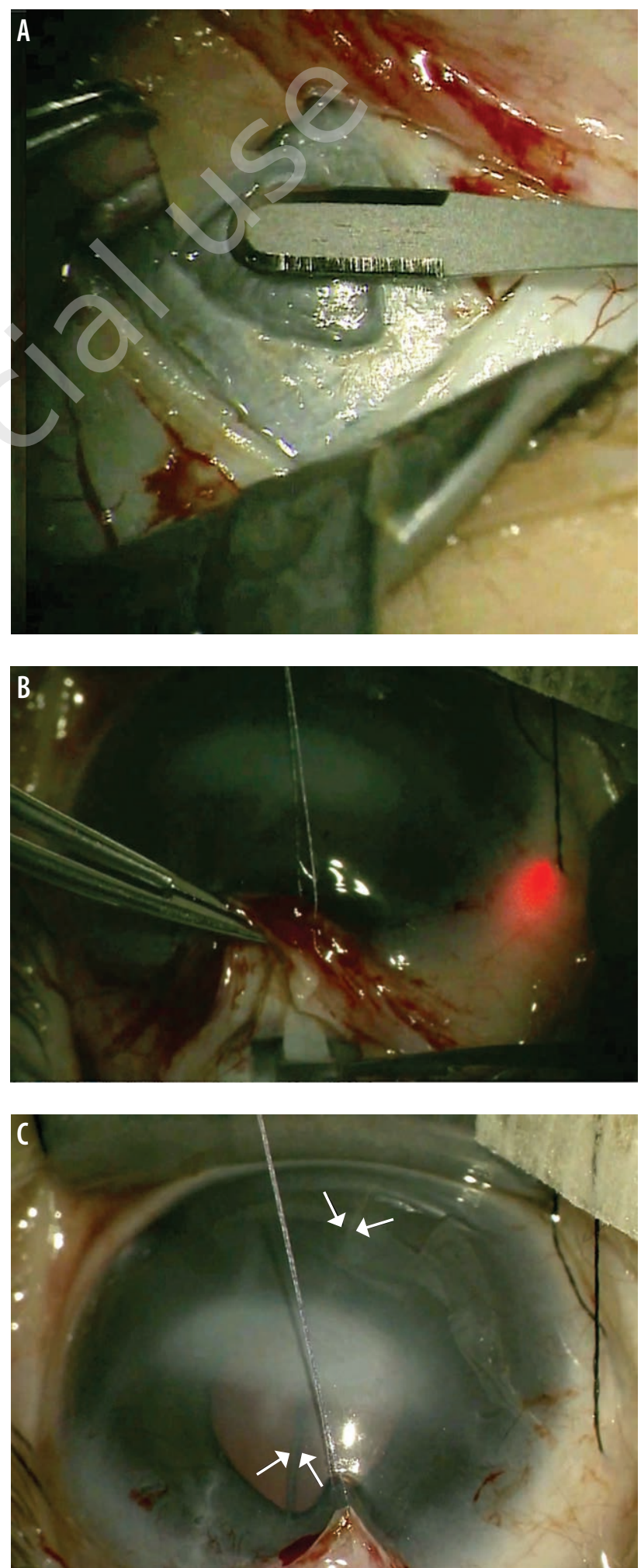


\section{Trabeculectomy}

Trabeculectomy for congenital glaucoma is considered a secondary procedure in cases when one or more angle procedures have failed [25]. If used in this situations, mitomycin C (MMC) should be used to reduce excessive wound healing. The use of MMC must be discussed with the child's parents and an individual consent form should be signed. In these situations, trabeculectomy may be a reasonable choice before a tube implant is considered. Khalil and Abdelhakim [26] reported favorable success of combined trabeculotomy-trabeculectomy with MMC in a prospective comparative series.

\section{Cyclophotocoagulation and cyclocryotherapy}

Cycloablation can be used as an intermediate approach to gain time or bridge a situation where immediate additional incisional surgery may have unacceptable risks or is not accepted by the parents $[27,28]$. In some cases, the IOP lowering effect may also persist. In Sturge-Weber syndrome where filtering procedures may be risky due to choroidal haemangiomas that could lead to choroidal hemorrhages, cycloablative procedures may lower IOP by occluding the intrascleral vessels (personal observations). In these cases, cyclocryotherapy may be preferable as it leads to a more extended areas of vascular occlusion. Care must be taken to maintain enough distance from the limbus to avoid severe complications. Although a distance $3.5 \mathrm{~mm}$ posterior to the limbus is centered over the pars plana [29], this technique aims at vascular occlusion more than ablation of ciliary secretory epithelium. In aphakic children with secondary glaucoma, endocyclophotocoagulation may be an alternative [30].

\section{Tube drainage implants}

Valved (Ahmed) and non-valved (Baerveldt) tube implants are mostly used in advanced cases of pediatric glaucoma when previous surgeries have failed [31, 32]. An overview of the literature on drainage tube implants is given by Werner and Grajewski [33]. The valved implant has the advantage of better avoiding hypotony, but due to the smaller plate size the resulting IOP is somewhat higher than with the non-valved implants. There are observations of retrograde ingrowth of fibrous tissue into the flow restrictor area of Ahmed implants. The non-valved implants afford more secondary interventions (removal of ligation sutures and or stenting sutures) which may be more stressful in small babies who need general anaesthesia for each intervention. In our practice, tube implants are not used as a primary procedure, even in secondary congenital or aphakic glaucoma. Due to the long life expectancy of glaucoma children, the cumulative risk of corneal endothelial damage is one of the arguments for this reluctant attitude.

Recently, a combination of (intracameral) MIGS implant $\left(\mathrm{XEN}^{\circledR}\right.$ or PreserFlo ${ }^{\circledR}$ ) connected to an (extraocular) Baer- veldt implant was used for severe childhood glaucoma in a small series of 10 eyes. The smaller tube in the anterior chamber might be less harmful to the corneal endothelium over the long life span of these children [34]. Results were promising, but further research is needed to prove efficacy and long-term outcome.

In general, tube drainage implants need to be part of the armamentarium in advanced cases after failed previous surgery.

\section{PERI- AND POSTOPERATIVE CARE, FOLLOW-UP}

It is essential to define the postoperative follow-up for each individual case. In our own routine, babies and small children ( $<2$ years) are admitted to the Pediatric Department, whereas older children (with their accompanying mother or father) are admitted to the Ophthalmology Department in Germany. In other countries, children are operated on an out-patient basis. It is essential to have a thorough examination on the first postoperative day to ensure (1) that there is no hypotony or an inadvertent (i.e. paracentesis-) fistula, (2) that the conjunctival wound is closed, (3) that the anterior chamber is not shallow or flat, and (4) that there is no or only minor bleeding in the anterior chamber. The IOP can be estimated by digital palpation through the eyelid. If there is doubt about the situation, in particular if the eye is soft, fundus examination (red light reflex) or - if necessary - ultrasound examination through the eyelid should rule out bullous choroidal detachment on the second postoperative day. We recommend steroid and antibiotic drops t.i.d. for 1 week. After trabeculotomy, pilocarpine eye drops (1\%) are given b.i.d for ciliary muscle contraction in order to keep the trabeculotomy cleft open. In very small babies, the concentration of pilocarpine must be reduced $(0,5 \%)$ as pylorospasm may develop due to systemic resorption of the parasympathomimetic. If the child tolerates pilocarpine well this treatment should be continued for 3 weeks.

In uncomplicated cases we recommend follow-up examinations after 1 week, preferably by the surgeon or his team, thereafter at 1 month (in critical cases earlier by the surgical team), 3 months and 1 year by the local ophthalmologist or by the surgical team. However, follow-up must be modified according to the type of surgery and customized to the complexity of the individual case. According to our experience families with members of childhood glaucoma are well adherent. Continuous exchange and mutual discussion of examination results is often requested.

Postoperative counseling should also discuss the genetic background of the respective type of congenital glaucoma. Testing of the major gene defects has now become available and is strongly recommended. The same phenotype may be present in different gene defects that may be dominantly or recessively inherited. This might be of importance for future family planning of the parents or the affected individual. 
After congenital glaucoma surgery it is mandatory to control and manage early visual development by an experienced team of orthoptic specialists in order to avoid amblyopia by adequate refractive measures and amblyopia treatment.

\section{SOME SURGICAL OBSERVATIONS WITH CIRCUMFERENTIAL TRABECULOTOMY IN SEVERAL TYPES OF CHILDHOOD GLAUCOMA}

It is our surgical experience from circumferential trabeculotomy with the illuminated microcatheter that Schlemm's canal is also patent in secondary congenital glaucoma immediately after birth and even in premature babies. With proper dissection of the scleral approach to Schlemm's canal (see above) and patient probing with the illuminated microcatheter using viscoelastics for dilatation and external deformation of the limbus in case of an obstacle it is possible to complete probing in most cases. If the catheter irreversibly stops after more than half of the circumference it is also possible to open the sclera over the tip of the catheter and perform a partial trabeculotomy. Otherwise the clear exposure of the ostia of Schlemm's canal with this technique allows to switch to a metal probe trabeculotome. In Axenfeld-Rieger syndrome, despite successful probing of Schlemm's canal, the trabecular meshwork seems to be firmer than in other types and could not be ripped with the catheter in several cases without exerting uncommon force. In these cases, the operation was transformed into a metal probe trabeculotomy to avoid tearing off the iris base. The iris strands per se in Axenfeld-Rieger syndrome do not preclude the attempt of circumferential trabeculotomy.

Several cases of aniridia were successfully operated with circumferential trabeculotomy. Probing and opening the trabecular meshwork was surprisingly easy and even possible in one eye of a premature baby (1700 g).

If the cornea is cloudy and visualization of the anterior chamber is hampered such as in Peters anomaly or Congenital corneal opacity (CCO), staining the intraluminal viscoelastic of the catheter with trypan blue (VisionBlue ${ }^{\circledR}$ ) makes the catheter better visible during the tearing of the trabecular meshwork.

Aphakic glaucoma is often characterized by failure of conventional surgical procedures and requires tube shunt implants, in particular when the angle is closed in later stages. However, we and others experienced favorable results with the use of illuminated microcatheter circumferential trabeculotomy in aphakic glaucoma $[35,36]$. From these observations, primary tube implants for aphakic glaucoma may not be needed as frequently as hitherto used.

Figures: from the author's own materials.

ORCID

Franz Grehn- ID - http://orcid.org/0000-0003-4238-982X

\section{References}

1. Weinreb RN, Grajewski AL, Papadopoulos M et al (ed). Childhood Glaucoma. WGA Consensus Series 9, Kugler Publ. 2013.

2. Grehn F, Prost M. Function of Retinal Nerve Fibers Depends on Perfusion Pressure: Neurophysiologic Investigations During Acute Intraocular Pressure Elevation. Invest Ophthalmol Vis Sci. 1983; 24: 347-53.

3. Grehn F. Congenital Glaucoma Surgery: A Neglected Field in Ophthalmology? Br J Ophthalmol. 2008; 92: 1-2.

4. Barkan O. Operation for congenital glaucoma. Am J Ophthalmol. 1942; 25: 552-68.

5. Papadopoulos M, Khaw P. Goniotomy and Trabeculotomy. In: Shaarawy TM, Sherwood MB. Glaucoma. Vol. 2. Surgical Management. Chap 120. Hitchings, Crowston Eds, Elsevier 2015: 1129-36.

6. Meyer G, Schwenn O, Grehn F. Trabeculotomy in congenital glaucoma: comparison to goniotomy. Ophthalmologe. 2000; 97: 623-8.

7. Girkin CA, Rhodes L, McGwin G et al. Goniotomy Versus Circumferential Trabeculotomy With an Illuminated Microcatheter in Congenital Glaucoma. J AAPOS. 2012; 16(5): 424-7.

8. Smith R. A new technique for opening the canal of Schlemm. Preliminary report. Br J Ophthalmol. 1960; 44: 370-4.

9. Allen L, Burian HM. Trabeculotomy ab externo. A new glaucoma operation: technique and results of experimental surgery. Am J Ophthalmol. 1962; 53: 19-26.

10. Luntz MH, Livingston DG. Trabeculotomy ab externo and trabeculectomy in congenital and adult-onset glaucoma. Am J Ophthalmol. 1977; 83: 174-9.

11. McPherson SD Jr, McFarland D. External trabeculotomy for developmental glaucoma. Ophthalmology. 1980; 87: 302-5. 
12. Harms H, Dannheim R. Erfahrungen mit der Trabekulotomie ab externo beim angeborenen Glaukom. Ber Dtsch Ophthalmol Ges. 1969; 69: 272-6.

13. Sampaolesi R. Die Trabekulotomie als erste Operation für das kongenitale Glaukombei Kindern bis zum 1. Lebensjahr. Ber Dtsch Ophthalmol Ges. 1972; 71: 645-47.

14. Al Hazmi A, Awad A, Zwaan J et al. Correlation between surgical success rate and severity of congenital glaucoma. Br J Ophthalmol. 2005; 89: 449-5.

15. Temkar S, Gupta S, Sihota R et al. Illuminated microcatheter circumferential trabeculotomy versus combined trabeculotomy-trabeculectomy for primary congenital glaucoma: a randomized con trolled trial. Am J Ophthalmol. 2015; 159: 490-7.

16. Mandal AK, Naduvilath TJ, Jayagandan A. Surgical results of combined trabeculotomy-trabeculectomy for developmental glaucoma. Ophthalmology. 1998; 105: 974-82.

17. Beck AD, Lynch MG. 360 degrees trabeculotomy for primary congenital glaucoma. Arch Ophthalmol. 1995; 113: 1200-2.

18. Sarkisian SR Jr. An illuminated microcatheter for 360-degree trabeculotomy in congenital glaucoma: a retrospective case series. J AAPOS. 2010; 14: 412-16.

19. Toshev AP, Much MM, Klink T et al. Catheter-assisted 360-Degree Trabeculotomy for Congenital Glaucoma. J Glaucoma. 2018; 27: 572-7.

20. Shakrawal J, Bali S, Sidhu T et al. Randomized Trial on Illuminated-Microcatheter Circumferential Trabeculotomy Versus Conventional Trabeculotomy in Congenital Glaucoma. Am J Ophthalmol. 2017; 180: 158-64.

21. El Sayed Y, Gawdat G. Two-year results of microcatheter-assisted trabeculotomy in paediatric glaucoma: a randomized controlled study. Acta Ophthalmol. 2017; 95: e713-e19.

22. El Sayed YM, Gawdat GI. Microcatheter-assisted Trabeculotomy Versus 2-site Trabeculotomy With the Rigid Probe Trabeculotome in Primary Congenital Glaucoma. J Glaucoma. 2018; 27: 371-6.

23. Celea C, Dragosloveanu S, Pop M et al. Comparison of 360-Degree Circumferential Trabeculotomy and Conventional Trabeculotomy in Primary Pediatric Glaucoma Surgery: Part 1. J Pediatr Ophthalmol Strabismus. 2016; 53: 357-64.

24. Neustein RF, Beck AD. Circumferential Trabeculotomy Versus Conventional Angle Surgery: Comparing Long-term Surgical Success and Clinical Outcomes in Children With Primary Congenital Glaucoma. Am J Ophthalmol. 2017; 183: 17-24.

25. Ko F, Papadopoulos M, Khaw PT. Primary congenital glaucoma. Prog Brain Res. 2015; 221: 177-89.

26. Khalil DH, Abdelhakim MA. Primary trabeculotomy compared to combined trabeculectomy-trabeculotomy in congenital glaucoma: 3-year study. Acta Ophthalmol. 2016; 94: e550-e4.

27. Kirwan JF, Shah P, Khaw PT. Diode Laser Cyclophotocoagulation: Role in the Management of Refractory Pediatric Glaucomas. Ophthalmology. 2002; 109: 316-23.

28. Sood S, Beck AD. Cyclophotocoagulation Versus Sequential Tube Shunt as a Secondary Intervention Following Primary Tube Shunt Failure in Pediatric Glaucoma. AAPOS. 2009; 13: 379-83.

29. Prost M, Witschel H, Mackensen G. Topographic-metric relations between the corneal limbus, chamber angle, iris and ciliary body. A contribution to "surgical anatomy". Klin Monbl Augenheilkd. 1982; 181: 490-2.

30. Cantor AJ, Wang J, Li S et al. Long-term efficacy of endoscopic cyclophotocoagulation in the management of glaucoma following cataract surgery in children. J AAPOS. 2018; 22: 188-91.

31. Chen A, Yu F, Law SK et al. Valved Glaucoma Drainage Devices in Pediatric Glaucoma: Retrospective Long-term Outcomes. JAMA Ophthalmol. 2015; 133: 1030-5.

32. Daniel MC, Mohamed-Noriega J, Petchyim S et al. Childhood Glaucoma: Long-Term Outcomes of Glaucoma Drainage Device Implantation Within the First 2 Years of Life. J Glaucoma. 2019; 28: 878-83.

33. Werner M, Grajewski A. Further surgical options in children. In: Shaarawy TM, Sherwood MB. Glaucoma. Surgical management Vol. 2 , Chap. 121. Shaarawy, Sherwood, Hitchings, Crowston Eds., Elsevier 2015: 1137-49.

34. Arad T, Hoffmann EM, Prokosch-Willing V et al. XEN-augmented Baerveldt Implantation for Refractory Childhood Glaucoma: A Retrospective Case Series. J Glaucoma. 2019; 28: 1015-8.

35. Brookes J, Trab/Trabeculotomy - a debate. International Congress of Glaucoma Surgery (ICGS). London, February $6^{\text {th }}-9^{\text {th }}, 2019$.

36. Dao JB, Sarkisian SR Jr, Freedman SF. Illuminated microcatheter-facilitated 360-degree trabeculotomy for refractory aphakic and juvenile open-angle glaucoma. J Glaucoma. 2014; 23: 449-54.

Wkład autorów:

Wszyscy autorzy mają taki sam wkład w opracowanie idei i konstrukcji artykułu.

Konflikt interesów:

Nie występuje.

Finansowanie:

Nie występuje.

Etyka:

Treści przedstawione w artykule są zgodne z zasadami Deklaracji Helsińskiej,

dyrektywami EU oraz ujednoliconymi wymaganiami dla czasopism biomedycznych.
Authors' contributions:

All authors have equal contribution to the paper.

Conflict of interest:

None.

Financial support:

None.

Ethics:

The content presented in the article complies with the principles of the Helsinki Declaration, EU directives and harmonized requirements for biomedical journals. 